\title{
Alat Penyortir Buah Tomat Berdasarkan Warna Berbasis Mikrokontroller Arduino
}

\author{
Alberth David Hetharua ${ }^{* 1}$, Sumarno ${ }^{2}$, Indra Gunawan ${ }^{3}$, \\ Dedy Hartama ${ }^{4}$, Ika Okta Kirana ${ }^{5}$ \\ 1,2,3,4,5Teknik Informatika, STIKOM Tunas Bangsa Pematangsiantar, Indonesia \\ Email: ${ }^{1}$ alberth.saragih@gmail.com, ${ }^{2}$ sumarno@gmail.com, ${ }^{3}$ indra@ amiktunasbangsa.ac.id, \\ ${ }^{4}$ dedyhartama@amiktunasbangsa.ac.id, 5ikaokta@amiktunasbangsa.ac,id
}

\begin{abstract}
Abstrak
Tomat merupakan salah satu jenis buah yang sangat digemari oleh masyarakat umum, karena buah tomat memiliki komposisi zat yang cukup lengkap serta banyak mengandung vitamin A, C, E juga kalium, kalsium dan garam. Namun dibalik banyaknya manfaat serta kegunaan buah tomat terdapat beberapa masalah ataupun kendala yang sering terjadi di dalam proses pemilihan hasil buah tomat, dikarenakan pengerjaannya yang masih manual atau bergantung pada persepsi manusia dalam memperhitungkan tingkat kematangan berdasarkan warna buah tomat tersebut. Banyak terjadi kesalahan, seperti data yang tidak akurat karena perbedaan persepsi dalam penentuan kematangan dan pengerjaannya terbilang lambat. Oleh karena itu, dibangun sebuah alat yang dapat melakukan pemilihan buah tomat berdasarkan warna berbasis Mikrokontroller Arduino, dimana alat ini dapat mengelompokkan buah tomat secara otomatis dan cepat sehingga lebih efektif dan lebih akurat serta mengefisenkan waktu, tenaga maupun biaya.
\end{abstract}

Kata kunci: Arduino Uno, Buah Tomat, Penyortiran

\section{Abstract}

Tomato is one type of fruit that is very popular with the general public, because tomatoes have a fairly complete composition of substances and contain lots of vitamins $A, C, E$ as well as potassium, calcium and salt. But behind the many benefits and uses of tomatoes, there are several problems or obstacles that often occur in the process of selecting tomato fruit, because the process is still manual or depends on human perception in calculating the level of maturity based on the color of the tomato. Many errors occur, such as inaccurate data due to differences in perception in determining maturity and the process is fairly slow. Therefore, a tool is built that can select tomatoes based on color based on the Arduino Microcontroller, where this tool can group tomatoes automatically and quickly so that it is more effective and more accurate and saves time, energy and costs.

Keywords: Arduino Uno, Sorting, Tomatoes

\section{PENDAHULUAN}

Teknologi sangat berperan penting untuk mendukung kinerja manusia di dalam berbagai bidang aspek kehidupan. Dewasa ini, perkembangan teknologi semakin pesat, hal itu juga menuntut agar kinerja teknologi dapat mempermudah dan mempercepat kinerja manusia dalam menyelesaikan pekerjaan serta menghasilkan hasil yang lebih baik pada segi efektivitas dan efesiensi. Salah satu teknologi pendukung kinerja manusia yang masih terus berkembang adalah teknologi untuk mengolah hasil industri dalam bidang pertanian dan perkebunan. Khususnya dalam pemilihan produk berdasarkan kualitasnya. Proses pemilihan produk, biasanya masih dilakukan secara manual atau bergantung pada persepsi manusia dalam memperhitungkan kematangan berdasarkan warna buah.

Tomat merupakan salah satu jenis buah yang sangat digemari, disamping buah tomat mengandung banyak vitamin, buah tomat juga sering sekali digunakan sebagai sayuran. Namun pemilihan hasil buah tomat juga sering mengalami kesalahan, dikarenakan pengerjaannya yang masih manual untuk membedakan kematangan buah tomat tersebut. Banyak terjadi kesalahan, seperti data yang tidak akurat karena perbedaan persepsi dalam penentuan kematangan dan pengerjaannya terbilang lambat. 
Oleh karena itu dibangun sebuah alat yang dapat melakukan pemilihan buah tomat berdasarkan warna sehingga dengan demikian dapat mengelompokkan buah yang lebih akurat dan mengefisen waktu, tenaga serta biaya.Maka pada penelitian ini, penulis tertarik untuk mengambil judul Alat Penyortir Buah Tomat Berdasarkan Warna Berbasis Arduino. Penulis membangun alat penyortir yang dapat mempermudah pengerjaan pengolahan hasil buah tomat.

\subsection{Tomat}

Tomat yang memiliki nama latin Solanum Lycopersicum merupakan tanaman yang berasal dari benua Amerika. Tanaman tomat cenderung memiliki siklus hidup yang cukup singkat serta tinggi tanaman yang dapat mencapai 1 sampai 3 meter. Buah tomat ini berasal dari keluarga terung-terungan atau solanaceae dan termasuk ordo solanales. Pada penelitian ini contoh buah tomat bisa dilihat pada gambar di bawah ini:

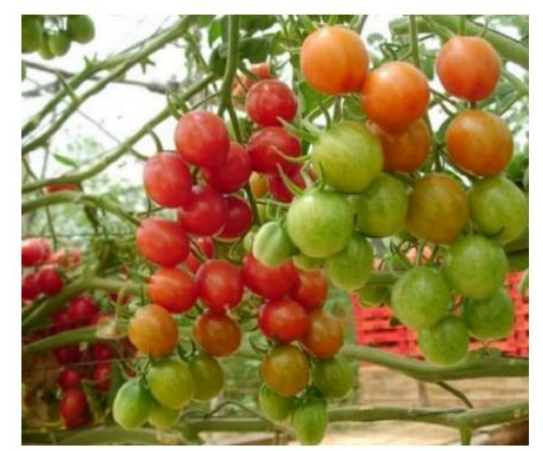

Gambar 1. Buah Tomat

Buah tomat merupakan salah satu buah yang memiliki warna yang kompleks suntuk menentukan kematangannya. Buah tomat memiliki 3 warna untuk menentukan apakah buat tomat tersebut sudah matang, setengah matang, dan mentah, yaitu warna merah ketika buah tomat sudah matang, warna kuning ketika buah tomat setengah matang, dan warna hijau ketika buah tomat mentah. Untuk menentukan kematangan buah tomat tersebut tidak hanya dilakukan secara konvensional (manual), tetapi bisa juga dapat dilakukan secara komputing (berbasis teknologi) (Nasution \& Fadillah, 2019).

Menurut Kementrian Pertanian Republik Indonesia, produksi buah tomat cenderung meningkat dari 891.616 ton pada tahun 2010, menjadi 976.772 ton pada tahun 2018 dan terus meningkat di tahun 2019 menjadi 1.020.331,00 ton. Selain beragamnya kegunaan buah tomat, rasa yang ditawarkan oleh buah ini juga cukup lezat. Buah tomat juga memiliki komposisi zat yang cukup lengkap serta vitamin A, C, E juga kalium, kalsium dan garam. Hal tersebutlah yang memberikan kontribusi besar terhadap nilai jual pasar sehingga membuat produksi tomat dari tahun ke tahun terus meningkat.

\subsection{Mikrokontroller Arduino}

Arduino Uno adalah papan sirkuit berbasis mikrokontroler ATmega328. IC (Integrated Circuit) ini memiliki 14 input/output digital (6 output untuk PWM), 6 analog input, resonator kristal keramik 16 $\mathrm{MHz}$, Koneksi USB, soket adaptor, pin header ICSP, dan tombol reset. Hal inilah yang dibutuhkan untuk mensupport mikrokontroler secara mudah terhubung dengan kabel power USB atau kabel power supply adaptor AC ke DC atau juga battery (Munandar \& Kamal, 2019).

Kemajuan Teknologi Mikrokontroler saat ini sudah sampai pada penggunaan Mikrokontroller denganberbagai platform open source seperti Arduino Uno. Untuk mengaktifkan Arduino Uno hanya langsung di hubungkan ke komputer dengan kabel USB atau menggunakan adaptor AC ke DC serta menggunakan baterai. Untuk dayanya (Abimanyu et al., 2021).

Mikrokontroler yang ada pada arduino tersebut bertugas sebagai otak yang mengendalikan sistem. Dengan adanya mikrokontroler yang terdapat pada arduinodapat mempermudah kinerja system serta penggunaan arduino dapat disesuaikan sesuai dengan kebutuhan. Sudah banyak hasil perangkat yang 
dibuat menggunakan arduino karena kemudahannya dalam memproses sistem dari yang sederhana hingga yang rumit. Untuk penggunaan arduino itu sendiri harus ditambah dengan sensor atau perangkat lainnya.Berikut merupakan hasil sebuah sistem yang dibuat menggunakan arduino seperti, MP3 Player, pengontrol monitor, pengontrol suhu, pengukur jarak, monitoring bensin bahkan sampai ke bidang musik seperti pembuatan alat musik drum elektronik.

Ada berbagai jenis papan Mikrokontroler Arduino menggunakan tipe chipset Atmega yang berbeda-beda dan disesuaikan sesuai dengan kebutuhan dan spesifikasinya. Pada penelitian ini contoh Arduino Uno bisa dilihat pada gambar di bawah ini:

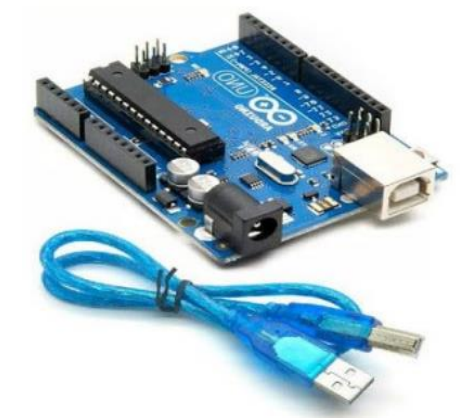

\section{Gambar 2. Mikrokontroller Arduino}

Mikrokontroler Arduino ini dilengkapi dengan konektor USB untuk memungkinkan pemrograman prosessor dari PC. Arduino juga dapat diprogram dengan menggunakan In System Programming (ISP). Terdapat 14 pin digital Arduino yang dapat digunakan sebagai input atau output dan 6 pin analog dengan nama A0 sampai A5, setiap pin analog memiliki resolusi sebesar 10 bit.

\subsection{Color Sensor TCS3200}

Module Sensor Warna TCS3200 menggunakan chip TAOS TCS3200 RGB. Modul ini telah terintegrasi dengan 4 LED. Sensor Warna TCS3200 dapat mendeteksi dan mengukur intensitas warna tampak. Beberapa aplikasi yang menggunakan sensor ini diantaranya pembacaan warna, pengelompokkan barang berdasarkan warna, ambient light sensing and calibration, pencocokan warna, dan banyak aplikasi lainnya. Chip TCS3200 memiliki beberapa photo detector, dengan masing-masing filter warna yaitu, merah, hijau, biru, dan clear (Mandari \& Pangaribowo, 2016).

Berikut ini pada gambar di bawah ditunjukkan bentuk dari sensor warna TCS3200:

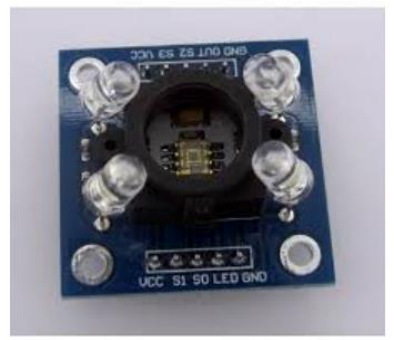

Gambar 3. Sensor Warna TCS3200

\subsection{Motor Servo}

Motor servo adalah sebuah perangkat atau aktuator putar (motor) yang dirancang dengan sistem kontrol umpan balik loop tertutup (servo), sehingga dapat di set-up atau di atur untuk menentukan dan memastikan posisi sudut dari poros output motor. motor servo merupakan perangkat yang terdiri dari motor DC, serangkaian gear, rangkaian kontrol dan potensiometer (Amin, 2020).

Pada penelitian ini, Motor Servo yang digunakan penulis bisa dilihat pada gambar di bawah ini: 


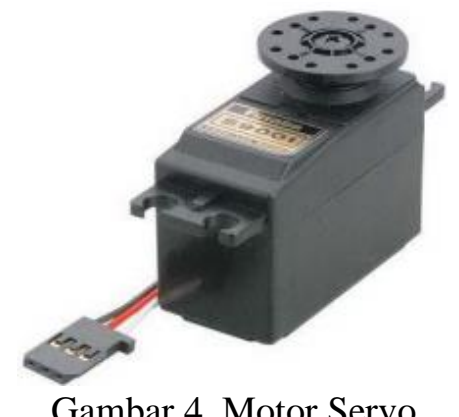

Motor servo merupakan sebuah motor dengan sistem closed feedback dimana motor servo ini dirancang untuk tugas-tugas yang lebih tepat dimana posisi harus jelas persis seperti menggerakkan lengan robot atau kaki robot dalam rentang tertentu. Biasanya motor servo sering digunakan dalam teknologi mesin perindustrian selain itu juga digunakan dalam berbagai aplikasi lain seperti pada mobil mainan radio kontrol, robot, pesawat, dan lain sebagainya.

\subsection{Buzzer}

Buzzer adalah sebuah komponen elektronika yang berfungsi untuk mengubah getaran listrik menjadi getaran suara. Pada dasarnya prinsip kerja buzzer hampir sama dengan loud speaker, jadi buzzer juga terdiri dari kumparan yang terpasang pada diafragma dan kemudian kumparan tersebut dialiri arus sehingga menjadi elektromagnet, kumparan tadi akan tertarik ke dalam atau keluar, tergantung dari arah arus dan polaritas magnetnya, karena kumparan dipasang pada diafragma maka setiap gerakan kumparan akan menggerakkan diafragma secara bolak-balik sehingga membuat udara bergetar yang akan menghasilkan suaraAkibat pergerakan mekanis pada buzzer, terjadilah perubahan energi dari energi listrik menjadi energi suara yang dapat didengar oleh manusia (Red, 2021).

Buzzer terdiri dari dua jenis, yaitu:

1. Active Buzzer, sering disebut dengan buzzer stand alone. Buzzer jenis ini sudah memiliki suaranya sendiri dan akan aktif apabila diberikan tegangan listrik.

2. Passive Buzzer, suara yang dihasilkan harus diprogram terlebih dahulu. Berbeda dengan active buzzer, kita dapat memprogram tinggi rendahnya nada pada buzzer jenis ini.

Spesifikasi komponen yang terdapat pada buzzer adalah sebagai berikut, yaitu:

1. Piezoelectric, yaitu berbentuk tabung berwarna hitam yang menjadi sumber keluarnya bunyi.

2. Kaki pin negatif, yaitu kaki buzzer yang pendek untuk dihubungkan ke arus negatif atau GND.

3. Kaki pin positif, yaitu pin kaki buzzer yang panjang dan gunanya untuk dihubungkan ke arus positif atau VCC $/ 5 \mathrm{~V}$.

Berikut di bawah ini pada gambar berikut buzzer yang penulis gunakan sebagai media suara.

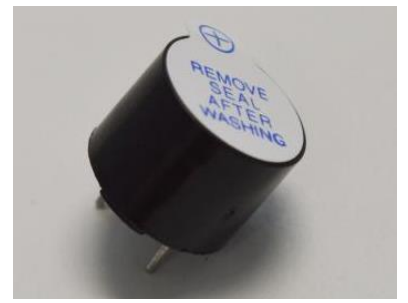

Gambar 5. Buzzer

\subsection{LCD (Liquid Crystal Display)}

Liquid Crystal Display merupakan komponen elektronika yang berfungsi sebagai output yang berbentuk visual atau sebagai media tampilan. Komponen ini menggunakan kristal cair (liquid crystal) untuk menghasilkan gambar dengan cara merefleksikan dan mentransmisikan cahaya yang melewatinya. Oleh sebab itu, LCD membutuhkan backlight atau cahaya latar belakang sebagai sumber 
cahayanya. Pada umumnya backlight pada LCD berwarna putih, sedangkan kristal cair (liquid crystal) merupakan cairan organik yang berada diantara dua lembar kaca yang memiliki permukaan transparan yang konduktif.

Pada penelitian ini, penulis menggunakan LCD dot matrik dengan jumlah karakter 2 x 16, dapat dilihat pada gambar di bawah ini:

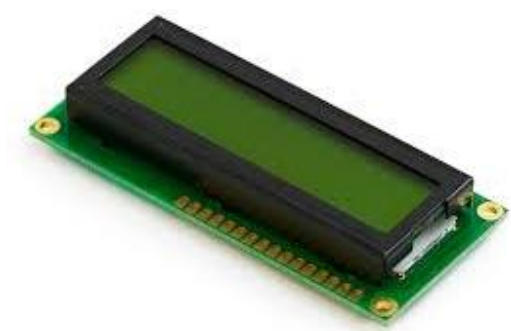

Gambar 6. Liquid Crystal Display

\subsection{Light Dependent Resistor (LDR)}

Light Dependent Resistor merupakan komponen elektronika jenis resistor yang mempunyai nilai yang dapat berubah-ubah tergantung intensitas cahaya yang menyinari permukaannya. Nilai resistansi dari LDR dikatakan sangat bergantung pada intensitas cahaya karena semakin banyak cahaya mengenai permukaan sensor, maka nilai resistansinya akan semakin menurun. Sebaliknya, jika semakin sedikit cahaya yang mengenai permukaan sensor, maka nilai hambatannya akan semakin besar sehingga arus listrik yang mengalir akan terhambat.

Light Dependent Resistor berfungsi sebagai sebuah sensor cahaya dalam berbagai macam rangkaian elektronika seperti saklar otomatis berdasarkan cahaya yang jika sensor terkena cahaya maka arus listrik akan mengalir (ON) dan sebaliknya jika sensor dalam kondisi minim cahaya (gelap) maka aliran listrik akan terhambat (OFF).

Contoh lain dalam pengaplikasian rangkaian sensor cahaya menggunakan LDR ini yaitu seperti penerangan lampu jalan yang akan otomatis menyala pada saat hari mulai gelap atau dalam kondisi malam, namun ketika hari mulai terang maka lampu jalan akan mati secara otomatis. Contoh lainnya yaitu, lampu kamar tidur, alarm bahkan rangkaian anti maling otomatis yang menggunakan laser, sutter kamera otomatis dan masih banyak contoh pengaplikasian Light Dependent Resistor lainnya.

Berikut di bawah ini pada gambar berikut merupakan Light Dependent Resistor (LDR) yang penulis gunakan sebagai media sensor.

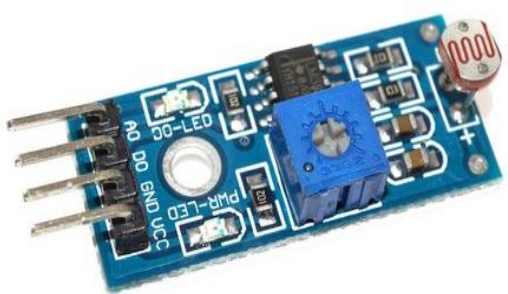

Gambar 7. Light Dependent Resistor

\subsection{Arduino IDE}

Arduino diciptakan untuk para pemula bahkan yang tidak memiliki basic bahasa pemrograman sama sekali karena menggunakan bahasa $\mathrm{C}++$ yang telah dipermudah melalui library. Arduino menggunakan Software Processing yang digunakan untuk menulis program kedalam Arduino. Processing sendiri merupakan penggabungan antara bahasa C++ dan Java (Zulita, 2016).

Arduino IDE adalah software atau perangkat lunak yang digunakan untuk melakukan pemrograman yang ada pada arduino. Aplikasi ini digunakan untuk membuat, membuka ataupun mengedit source code pada mikrokontroler arduino yang nantinya akan menjalankan proses pengerjaan sebuah sistem. 
Tampilan IDE Arduino dengan sebuah sketch yang sedang diedit dapat dilihat pada gambar di bawah ini.

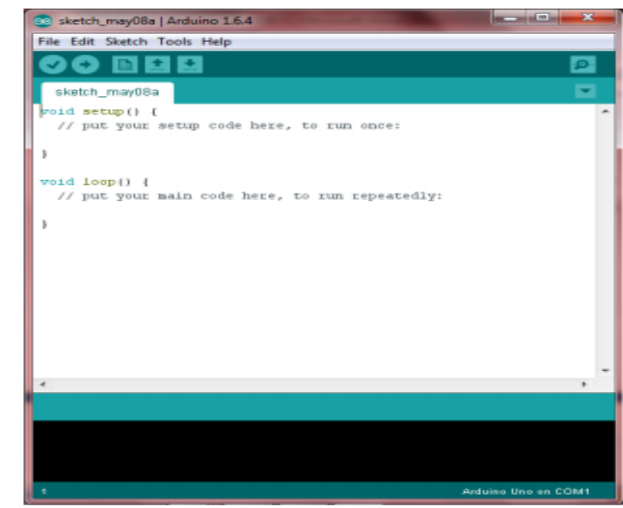

Gambar 8. Arduino IDE

\section{METODE PENELITIAN}

Metode penelitian merupakan langkah yang harus dilewati oleh peneliti dalam mendapatkan informasi dan jawaban guna mendapatkan jawaban tepat atas pertanyaan dalam objek penelitian atau upaya untuk mengetahui sesuatu dengan secara sistematis.

Pada penelitian ini penulis membahas tentang membangun alat penyortir buah tomat berdasarkan warna berbasis Miktokontroller arduino, Perancangan perangkat ini meliputi perangkat keras (Hardware) dan perangkat lunak (Software).

\subsection{Rancangan Penelitian}

Pada system alat penyortir buah tomat berdasarkan warna berbasis Miktokontroller arduino, penulis membuat beberapa tahapan perancanangannya, mulai dari pengambilan data sampai dengan pengolahan yang akan dibuat sehingga hasil outputnya lebih jelas.

Gambar Rancangan penelitian dapat dilihat ada gambar berikut.

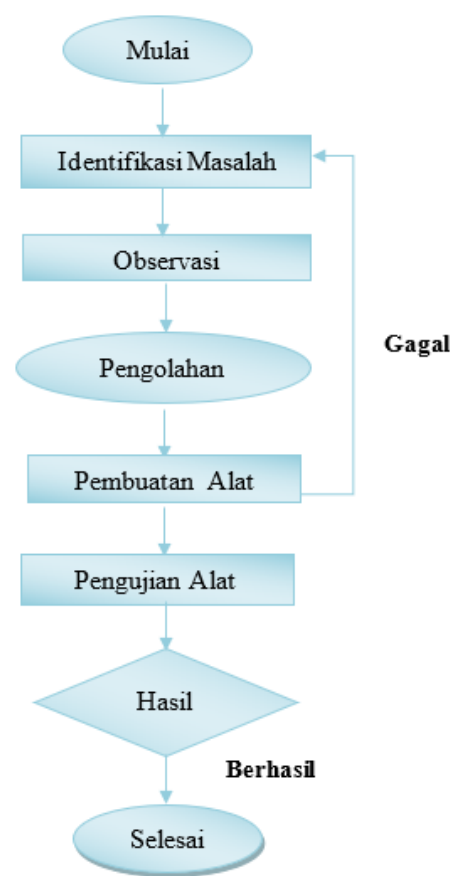

Gambar 9. Rangkaian Penelitian 
berikut:

Adapun penjelasan pada flowchart penelitian seperti pada gambar di atas dapat uraikan sebagai

1. Identifikasi Masalah

Salah satu proses yang paling penting dari sebuah penelitian ialah identifikasi masalah. Permasalahan penelitian yang didapat penulis saat ini ialah alat pemotong rumput konvensional yang masih jauh dari resiko keamanan dan serta menggunakan tenaga manusia yang berlebih seperti memikul alat pemotong.

2. Observasi

Mengamati dan mempertimbangkan alat pemotong rumput yang akan dibuat agar dapat berkerja dengan semestinya.

3. Pembuatan Alat

Rancang bangun alat yang nantinya dapat menyelesaikan permasalahan yang akan di pecahkan.

4. Pengujian Alat

Melakukan tahap uji coba alat pemotong rumput agar dapat bekerja dan dikendalikan sesuai yang diharapkan.

5. Hasil

Menghasilkan sebuah alat yang dapat diterapkan sesuai dengan rancangan.

\subsection{Perancangan Perangkat Keras}

Dalam meringankan perancangan sistem ini maka penulias akan memakai blok diagram untuk tahapan awal dalam proses pembuatannya, dimana blok diagram ini digunakan untuk menampilkan bagaimana cara kerja sistem ini dilakukan secara umum. Sistem rangkaian dapat dilihat pada gambar di bawah ini.

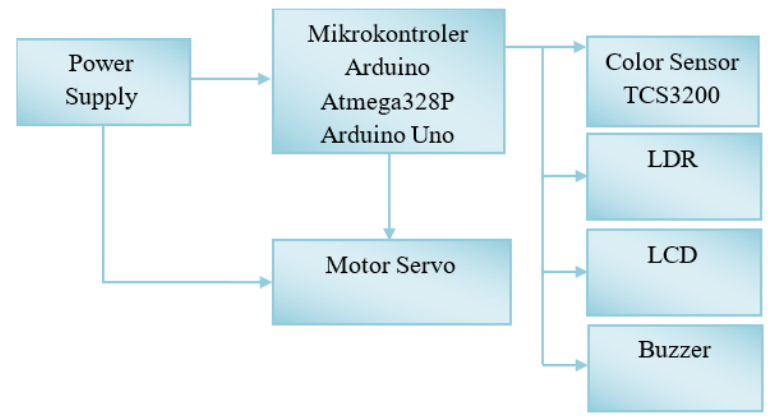

Gambar 10. Blok diagram

Pada gambar di atas merupakan beberapa perangkat keras pada alat penyortir buah tomat berdasarkan warna berbasis arduino, antara lain:

1. Power Supplymerupakan komponen yang berfungsi sebagai sumber energi atau sumber daya listrik pada rangkaian alat penyortir.

2. Mikrokontroler merupakan penghubung antara perangkat lunak dengan perangkat keras serta sebagai control utama yang berfungsi untuk mengendalikan sistem berupa sebuah IC Mikrokontroler seri Atmega328 pada Arduino Uno.

3. Color Sensor TCS3200 terdiri dari dua komponen utama penyusun yakni photo diode dan pengubah arus menjadi frekuensi (ADC) yang yang diprogram untuk mengkonversikan warna menjadi frekuensi dengan keluaran berupa sinyal kotak.

4. Motor Servo DC merupakan perangkat yang berfungsi sebagai penggerak dari pemilahan buah tomat yang telah dilewati sensor warna.

\subsection{Cara Kerja Alat}

Bagaimana sistem kerja alat bekerja dapat dilihat pada flowchart pada gambar di bawah ini. 


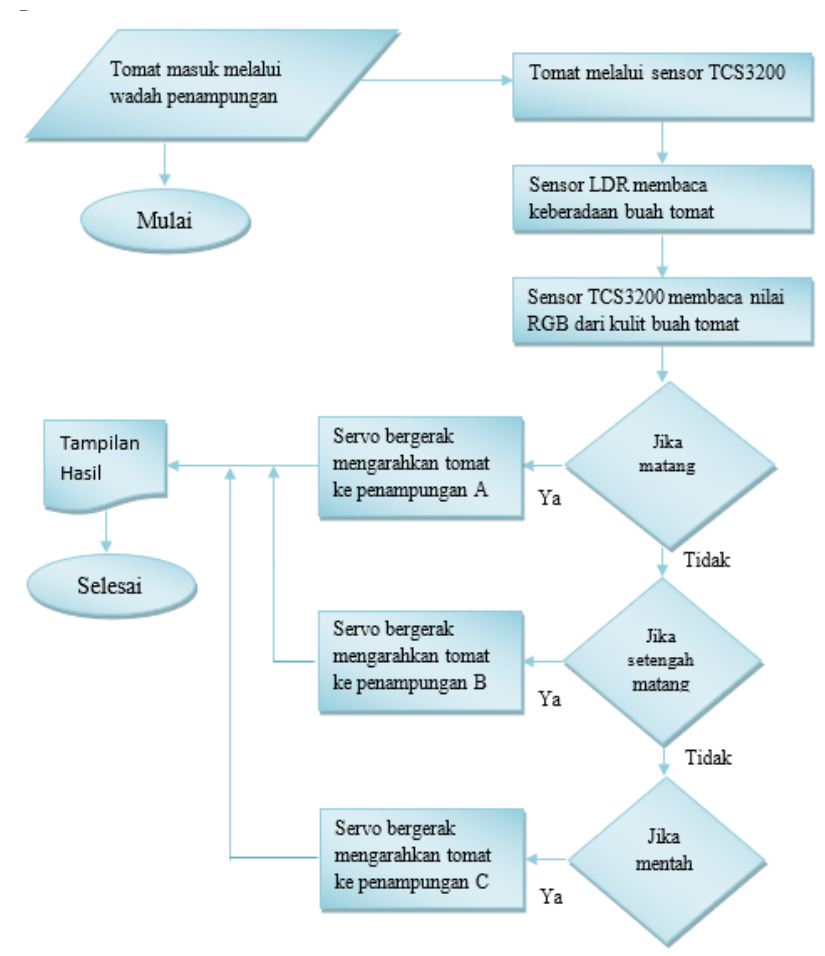

Gambar 11. Sistem Kerja Alat

Pada gambar di atas dijelaskan bahwa bagaimana langkah-langkah kinerja sistem dalam merancang sebuah alat penyortir buah tomat berdasarkan warna berbasis arduino menggunakan metode waterfall yang dimana pada saat alat dihidupkan dengan menekan sakelar $O N$ maka alat penyortir akan menyala. Kemudian alat akan menyeleksi buah tomat yang masuk pada mesin sortir.

Penyeleksian buah tomat dilakukan dengan penentuan kategori yang sudah ditetapkan sebelumnya yaitu buah tomat matang, setengah matang dan belum matang berdasarkan warna RGB yang telah diinput sebelumnya ke dalam sistem. Buah tomat yang telah diseleksi oleh sensor TCS3200 akan didorong motor-servo untuk masuk ke dalam wadah yang sudah ditentukan. Alat penyortir akan memilah buah tomat secara otomatissampai pengguna ingin berhenti menyortir dengan mematikan alat tersebut dengan menekan tombol sakelar $O F F$.

\section{HASIL DAN PEMBAHASAN}

Pada tahapan ini setelah menyelesaikan penulisan perancangan alat lalu di lanjutkan dengan tahapan pembuatan model kerja alat. Alat dapat bekerja dengan menghidupkan sakelar $O N$ kemudian alat akan melakukan pemilahan yang pertama kali diawali dengan antrian tomat yang akan dipilah satu per satu menggunakan motor servo, kemudian tomat akan di sensor oleh sensor warna TCS-3200. Setelah warna tomat telah terdeteksi oleh sensor warna, tomat akan bergerak menuju tempat atau wadah menggunakan motor servo dengan tiga kategori yaitu, matang, setengah matang dan belum matang dan hasil pemilahan akan ditampilkan di LCD $16 \times 2$. Alat akan terus melakukan penyortiran secara otomatis sampai buah tomat di dalam tempat pengantrian habis atau dengan cara menekan tombol sakelar $O F F$. Selanjutnya penulis akan menjabarkan manfaat, tujuan dan tahapan yang ada pada alat penyortir buah tomat ini.

Hasil dari proses perancangan alat yang akan dibuat dimulai dari proses pengantrian buah tomat dalam wadah sebelum di sortir menggunakan sensor TCS-3200 serta proses pemilahan buah tomat yang bergerak menuju wadah dengan dorongan motor servo serta alat penyusun lainnya yang saling terhubung satu dengan yang lain.

Adapun skema rangkaian keseluruhan Alat penyortiran buah tomat dengan Arduino dan sensor warna dapat dilihat pada gambar di bawah ini. 


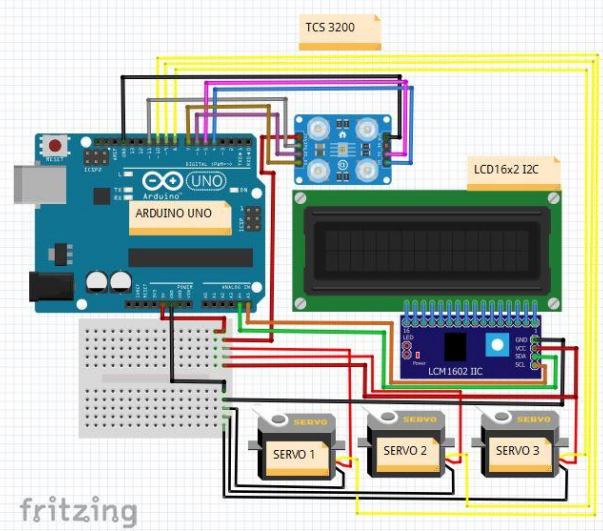

Gambar 12. Skema Rangkaian

Berdasarkan skema rangkaian pada gambar di atas instalasi dan penghubung arduino uno dengan komponen lainnya dapat dihubungkan antara dengan pin pada setiap modul, instalasi antar pin dapat dilihat sebagai berikut:

1. Pin GND dihubungkan ke pin GND TCS3200, GNDLcd 16x2 I2C, GND Servo

2. Pin 5V dihubungkan ke pin VCC TCS3200, VCC Lcd 16x2 I2C, VCC Servo

3. Pin $S C L(\mathrm{~A} 5)$ dihubungkan dengan pin $S C L L c d 16 \times 2$ I2C

4. Pin $S D A(\mathrm{~A} 4)$ dihubungkan dengan pin SDA Lcd 16x2 I2C

5. Pin 4 dihubungkan dengan pin S0 TCS 3200

6. Pin 5 dihubungkan dengan pin S1 TCS 3200

7. Pin 6 dihubungkan dengan pin S2 TCS 3200

8. Pin 7 dihubungkan dengan pin S3 TCS 3200

9. Pin 8 dihubungkan dengan pin IN Servol

10. Pin 9 dihubungkan dengan pin IN Servo2

11. Pin 10 dihubungkan dengan pin IN Servo3

12. Pn 11 dihubungkan dengan pin OUT TCS3200

Setelah antara pin saling terhubung sesuai dengan skema rangkaian yang dibuat, maka selanjutnya meng-upload kode program melalui program aplikasi Arduino IDE. Sehingga rangkaian yang dibuat dapat bekerja sesuai denganrancangan.

\subsection{Rangkaian Fisik Alat}

Rangkain fisik alat ini merupakan hasil dari perakitan yang dilakukan penulis dalam pembuatan alat penyortir buat tomat ini. Alat ini dapat dilihat seperti pada gambar sebagai berikut:

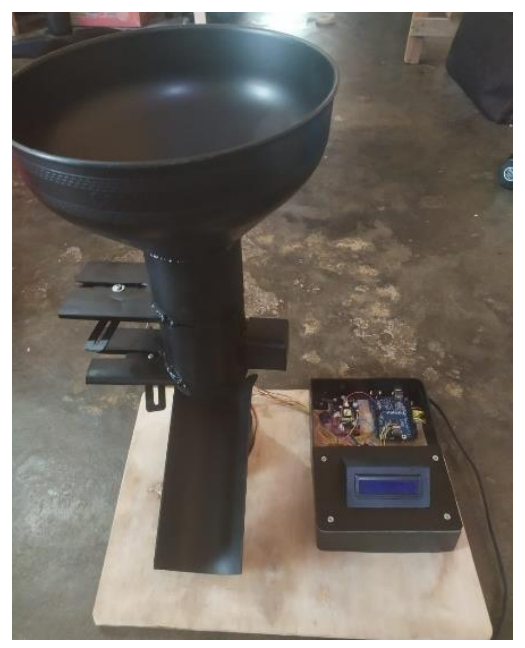

Gambar 13. Rangkaian alat 


\subsection{Pengujian Alat}

Pada prosesn pengujian alat ini tahap pertama yang dilakukan adalah dengan memberikan supplay daya arus sebesar $12 \mathrm{~V}$ ke papan arduino dan komponen lainnya seperti sensor warna TCS 3200 sebagai sensor pemilahan warna pada buah tomat, motor dc untuk memilah buat tomat, LCD 16 x 2 sebagai monitoring pemrosesan pemilahan, serta buzzer dan LDR yang mendeteksi keberadaan buah tomat yang akan dipilah.Tahap ini dilakukan untuk memastikan setiap alat seperti motor servo, LCD, LDR, buzzer dan sensor warna TCS 3200 dapat bekerja dengan semestinya.

Setelah alat siap dirancang dan dapat beroperasi, maka alat dapat bekerja melakukan penyortiran buah tomat secara otomatis yang dapat melakukan pemilahan secara terus menerus hingga buah tomat yang berada pada wadah antrian habis atau dengan cara menekan tombol sakelar $O F F$ agar alat berhenti melakukan penyortiran.

Alat ini berjalan dengan baik dan lancar dalam setiap proses penyortiran buah tomat ini dimana dapat mempermudah dan memberikan efesiensi waktu dan keakuratan dalam proses pemilhan buath tomat.

\subsection{Prosedur Sistem Kerja}

Dengan penggunaan alat penyortir buah tomat berdasarkan warna berbasis Arduino yang telah penulis rancang, akan divalidasikan dengan pengujian setiap komponen yang telah dirancang maka dalam hal ini alat untuk penyortiran buah tomat dapat membantu dalam proses pemilahan hasil buat tomat yang lebih efektif dan efisien.

1. Masukan (input)

Penulisan kode program yang akan di upload ke perangkat mikrokontroler arduino uno memerlukan bantuanprogram aplikasiarduino ide yang jenis bahasa pemrogramanya $\mathrm{C}++$, dilengkapi juga dengan menu library pada program sehingga mempermudah dalam penulisan kode, serta terdapatnya software preprocessing yang berguna untuk menuliskan program ke perangkatmikrokontroler arduino.

2. Pemrosesan (Procces)

Pada tahap ini data yang diterima kemudian akan diolah oleh perangkat mikrokontroler arduino. Hasil pemrosesan oleh perangkat mikrokontroler arduino akan dieksekusi sesuai dengan perintah atau kode program yang sebelumnya telah di uploadpada perangkat mikrokontroler.

3. Keluaran (Output)

Setelah arduino memproses perintah atau masukan yang ada selanjutnya arduino akan mengirim data berupa keluaran pada sensor warna TCS3200 dan motor-servo. Dimana buah tomat akan melaluisensor warna TCS3200 dan buah akan diarahkan dengan motor servo menuju wadah berdasarkan jenis buah (matang, setengah matang dan belum matang).

\section{KESIMPULAN}

Berdasarkan hasil uraian dari pembahasan sebelumnya serta hasil yang dilakukan selama melakukan penelitian dan pengujian alat absensi otomatis ini dirancang dengan memanfaatkan teknologi Radio Frequency Identification (RFID) maka dapat disumpulkan bahwasanya Alat ini dapat memudahkan pengerjaan pengembangan dalam hal penyortiran buah tomat, yang sebelumnya pekerjaan menyortir masih dilakukan secara manual disamping itu alat ini juga dapat memaksimalkan hasil dari penyortiran karena menggantikan penyortiran yang dilakukan secara kasat mata, namun dengan menggunakan sensor TCS 3200 ini dapat menjadi lebih akurat serta lebih efektif dan efisien, namun Untuk daya angkut yang lebih besar harus menggunakan motor servo yang lebih besar juga.

\section{DAFTAR PUSTAKA}

Abimanyu, D., Anggraini, F., Gunawan, I., \& Parlina, I. (2021). Rancang Bangun Alat Pemantau Kadar pH , Suhu Dan Warna Pada Air Sungai Berbasis Mikrokontroller Arduino Design And Construction Of pH Temperature And Color Monitoring Equipment In Water-Based River On Arduino Microcontroller. 1(6), 235-242. 
Amin, M. (2020). Sistem Cerdas Kontrol Kran Air Menggunakan Mikrokontroler Arduino dan Sensor Ultrasonic. InfoTekJar: Jurnal Nasional Informatika Dan Teknologi Jaringan, 2, 1-5.

Mandari, Y., \& Pangaribowo, T. (2016). Rancang Bangun Sistem Robot Penyortir Benda Padat. Jurnal Teknologi Elektro, 7(2), 106-113.

Munandar, T. I., \& Kamal, M. (2019). Temperatur Pada Proses Pemanggangan Ikan Tuna Secara Otomatis Menggunakan Arduino Uno Atmega328. 3(2), 75-80.

Nasution, M. S., \& Fadillah, N. (2019). Deteksi Kematangan Buah Tomat Berdasarkan Warna Buah dengan Menggunakan Metode YCbCr. InfoTekJar (Jurnal Nasional Informatika Dan Teknologi Jaringan), 3(2), 147-150. https://doi.org/10.30743/infotekjar.v3i2.1059

Red, I. (2021). Sistem Pendeteksi Objek untuk Keamanan Rumah dengan Menggunakan Sensor Infra Red. 1-17.

Zulita, L. N. (2016). PERANCANGAN MUROTTAL OTOMATIS MENGGUNAKAN MIKROKONTROLLER ARDUINO MEGA 2560. 12(1), 89-98. 


\section{Halaman Ini Dikosongkan}

